\title{
Development of a UV-spectrophotometric method for study of degradation profile of tenofovir alafenamide
}

\author{
M. P. Shinde ${ }^{1, *}$, Aishwarya Patil ${ }^{2}$, A. R. Bendale ${ }^{3}$, S.P. Narkhede ${ }^{4}$, A. G. Jadhav ${ }^{5}$ \\ ${ }^{\mathbf{1}}$ Assistant Professor, ${ }^{\mathbf{2}}$ Student, ${ }^{\mathbf{3} 4}$ Associate Professor, ${ }^{\mathbf{5}}$ Principal, Dept. of Pharmaceutical Chemistry, Sandip Institute of \\ Pharmaceutical Sciences, Nashik, Maharashtra, India \\ *Corresponding Author: M. P. Shinde \\ Email: madhavibochare@gmail.com
}

\begin{abstract}
Tenofovir alafenamide is a nucleic acid analogue that is used for treatment of HIV infection and Hepatitis B. As compared with the other prodrug of tenofovir, tenofovir alafenamide is having less side effects, it is Steady in plasma and then quickly changed over into tenofovir once inside cells. The main aim and objective of present study was to perform the stability indicating studies as defined under ICH Guideline Q1A R2) by using UV spectrophotometer. According to ICH guidelines, of temperature, time, photo degradation, acid/base are the factors which are responsible for formation degradation product of a drug. UV-Vis spectroscopy method was intiated to study and compute the amount of drug in the presence of degradation products. The method was developed by using water as diluents and $\lambda \max$ was $260 \mathrm{~nm}$. Linearity was established for in the range of $2-10 \mu \mathrm{g} / \mathrm{mL}$ with regression coefficient of 0.9912 . The drug was subjected to acid, alkali and neutral hydrolysis, oxidation degradation conditions. The limits of detection (LOD) and quantification (LOQ) were calculated and found to be $1.43 \mu \mathrm{g} / \mathrm{mL}$ and $4.33 \mu \mathrm{g} / \mathrm{mL}$, respectively. The method was found to be simple, economic and less time consuming as compared to other analytical techniques.
\end{abstract}

Keywords: Stability indicating assay method, Tenofovir alafenamide fumarate.

\section{Introduction}

Tenofovir alafenamide fumarate (TAF) is a nucleotide reverse transcriptase inhibitor (NRTI) and a new ester prodrug of the antiretroviral tenofovir. After oral administration, tenofovir alafenamide fumarate is converted in vivo to tenofovir, an acyclic nucleoside phosphonate (nucleotide) analog of adenosine 5'monophosphate. As compared to the other prodrug, TAF was found to be more Potent and it has eminent antiviral activity.

Pharmaceutical industry differs from other chemical industries in many aspects due to its direct relation with human lives. One of the challenges before pharmaceutical industry is control on impurities present in active pharmaceutical ingredients (API) as well as in drug products. Safety and quality of drug products may be hampered by impurities (even in low concentrations) present in API and drug products. Impurities result from chemical changes during drug manufacturing, storage and transportation in response to changes in light, temperature, $\mathrm{pH}$, and humidity, or due to inherent characteristics of the active pharmaceutical substance, such as their reaction with excipients or on contact with the packaging. Knowledge of the possible impurities which may be formed is required to develop the drug product, packaging, storage conditions and quality control strategies.

Due to the lower concentrations of impurities, these are difficult to detect and quantify. For some of the important drugs and their formulations, these challenges are proposed to be addressed in the present project by developing stability-indicating assay methods.
A literature survey revealed that development of validated stability-indicating assay methods have been reviewed by Bakshi et al in 2002. ${ }^{2}$ As this is novel oral prodrug of tenofovir, no spectroscopic and chromatographic methods were reported for its quantification in pure API and in dosage form.

\section{Materials and Methods}

Chemicals and Reagents: Pharmaceutical grade of tenofovir alafenamide fumarate was supplied by Lupin Pharmaceutical ltd, Aurangabad. Water of distilled grade was used.

Instruments: UV-Visible Spectrophotometer of Make Agilent with Model Carry-60 with cuvette of $1 \mathrm{~cm}$ was used for the absorbance measurement. Electronic Balance of Schimadzu with mdoel no $220 \mathrm{H}$ was used for weighing purpose. Ultra Sonicator of make wensar was used for sonication purpose.

Procedure: UV Spectrometric methods for determination of tenofovir alafenamide fumarate:

Selection of Solvent: The solvent was selected by critically examining solubility of drug in various solvents namely distilled water, $0.1 \mathrm{M} \mathrm{HCl}, 0.1 \mathrm{~N}$ $\mathrm{MaOH}$, Methanol. Finally, selected solvent was distilled water for tenofovir alafenamide fumarate preparation of standard stock solution: $20 \mathrm{mg}$ tenofovir alafenamide fumarate was accurately weighed and tranferred in a $100 \mathrm{~mL}$ volumetric flask and to it around $30 \mathrm{~mL}$ of distilled water was added. The solution was subjected to sonication. After that, the volume was made up to mark with distilled water to get the final concentration of $200 \mathrm{ppm}$. 
Preparation of Working Standard Solution of Tenofovir Alafenamide Fumarate: From the above stock solution, $1 \mathrm{~mL}$ was diluted upto $10 \mathrm{~mL}$ to obtain concentration $10 \mu \mathrm{g} / \mathrm{mL}$. Solution was scanned in the UV range i.e. from $200 \mathrm{~nm}$ to $400 \mathrm{~nm}$ and spectrum was recorder as showed in Fig 2.

\section{Method Validation}

Specificity: Specificity of the method was studied by measuring the absorbance of TAF individually at $260 \mathrm{~nm}$ against the blank and it was compared to check any interference.

Linearity and Range: Different dilution of concentration $5,10,15,20,25$ and $30 \mu \mathrm{g} / \mathrm{mL}$ of tenofovir alafenamide fumarate were prepared by diluting the $0.25,0.5,0.75,1.0,1.25,1.5 \mathrm{~mL}$ standard stock solution respectively. Final volume was made upto $10 \mathrm{~mL}$ with distilled water. Absorbances of each solution were noted down at $260 \mathrm{~nm}$. Then the caliberation cureve was ploteed and interpretated in terms of Coefficient of correlation $\left(\mathrm{R}^{2}\right)$ and the equation of line. The result were reported in Table 1.

Limit of Detection and Limit of Quantification: According to ICH guideline there are several methods reported to determine LOD and LOQ. These include visual evaluation, signal-to-noise ratio and the use of standard deviation of the response and the slope of the calibration curve. In the present study, the LOD and LOQ were calculated based on the third approach with the formula $3.3 \times(\mathrm{SD} / \mathrm{Slope})$ and $10 \times(\mathrm{SD} / \mathrm{Slope})$ criteria, respectively; where $\mathrm{SD}$ is the standard deviation of $y$-intercept of regression line and $S$ is the slope of the calibration curve.

\section{Force Degradation Studies}

Hydrolytic Degradation: Acid and alkaline degradation studies were performed by taking $1.5 \mathrm{~mL}$ of $200 \mu \mathrm{g} / \mathrm{mL}$ TAF separately in two $10 \mathrm{~mL}$ calibrated flasks and mixed with $5 \mathrm{~mL}$ of $1 \mathrm{M}$ hydrochloric acid (acid hydrolysis) and $5 \mathrm{~mL}$ of $1 \mathrm{M} \mathrm{NaOH}$ (base hydrolysis), respectively. Both the flasks were placed in water bath at $60^{\circ} \mathrm{C}$ for $2 \mathrm{~h}$. Then, the solution were cooled to room temperature and neutralized. Lastly final volume was made to the mark with water, and the absorbances were recorded.

Oxidation Studies: Oxidative degradation study was performed by using hydrogen peroxide solution 3\% at room temperature for $4 \mathrm{hr}$ and the absorbance of the resulting solutions was recorded.

Neutral degradation studies: Neutral degradation study was performed by using water and the solution was kept in water bath at $60^{\circ} \mathrm{C}$ for $4 \mathrm{hr}$ and the absorbance of solutions was recorded.

$\%$ degradation of all the solution were calculated and reported in Table 2.

\section{Result and Discussion}

An attempt has been made to develop rapid and specific SIAM for the tenofovir alafenamide fumarate in bulk. The developed UV method allows a Swift and low budget estimation of TAF. The method was found to be linear in the range of $5-30 \mu \mathrm{g} / \mathrm{mL}$. The linear regression equation of tenofovir alafenamide fumarate was $\mathrm{y}=0.0323 \mathrm{x}+0.0189$ with correlation coefficient value of $\left(\mathrm{R}^{2}\right) 0.9986$. The LOD and LOQ were found to be $1.13 \mu \mathrm{g} / \mathrm{mL}$ and $3.43 \mu \mathrm{g} / \mathrm{mL}$.

From our results we can conclude that, the TAF in acidic, basic, oxidative $(3 \% \mathrm{H} 2 \mathrm{O} 2)$ and neutral hydrolysis showed 13.8, 10.44, 12.19 and $13.16 \%$ degradation, respectively. The drug was found to be more prone to acid hydrolysis as compared to Alkaline.

Table 1: Calibration data for tenofovir alafenamide fumarate

\begin{tabular}{|l|c|c|}
\hline S. No. & $\begin{array}{c}\text { Concentration in } \\
\text { ppm }\end{array}$ & Absorbance \\
\hline 1 & 5 & 0.1690 \\
\hline 2 & 10 & 0.3569 \\
\hline 3 & 15 & 0.5120 \\
\hline 4 & 20 & 0.6528 \\
\hline 5 & 25 & 0.8215 \\
\hline 6 & 30 & 0.9925 \\
\hline
\end{tabular}

Table 2: Summary of degradation

\begin{tabular}{|l|c|c|c|c|}
\hline Degradation Condition & Time & $\begin{array}{c}\text { \% Assay of } \\
\text { degraded product }\end{array}$ & $\begin{array}{c}\text { Drug } \\
\text { decompose (\%) }\end{array}$ & Remark \\
\hline Water at $60^{\circ} \mathrm{c}$ & $4 \mathrm{~h}$ & $87.84 \%$ & $13.16 \%$ & Degradation \\
\hline $\mathrm{NaOH}$ at $60^{\circ} \mathrm{c}$ & $2 \mathrm{~h}$ & $90.56 \%$ & $10.44 \%$ & Less Degradation \\
\hline $\mathrm{HCL}$ at $60^{\circ} \mathrm{c}$ & $2 \mathrm{~h}$ & $89.92 \%$ & $11.08 \%$ & Degradation \\
\hline $\mathrm{H}_{2} \mathrm{O}_{2}(3 \%)$ at room temp. & $4 \mathrm{~h}$ & $88.81 \%$ & $12.19 \%$ & Degradation \\
\hline
\end{tabular}




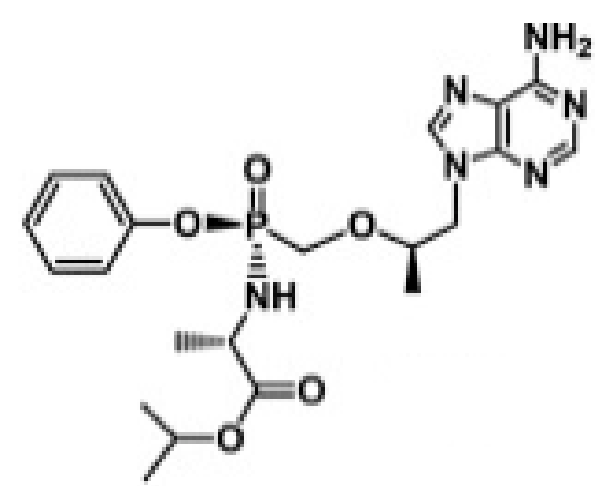

Fig. 1: Tenofovir alafenamide fumarate chemical structure

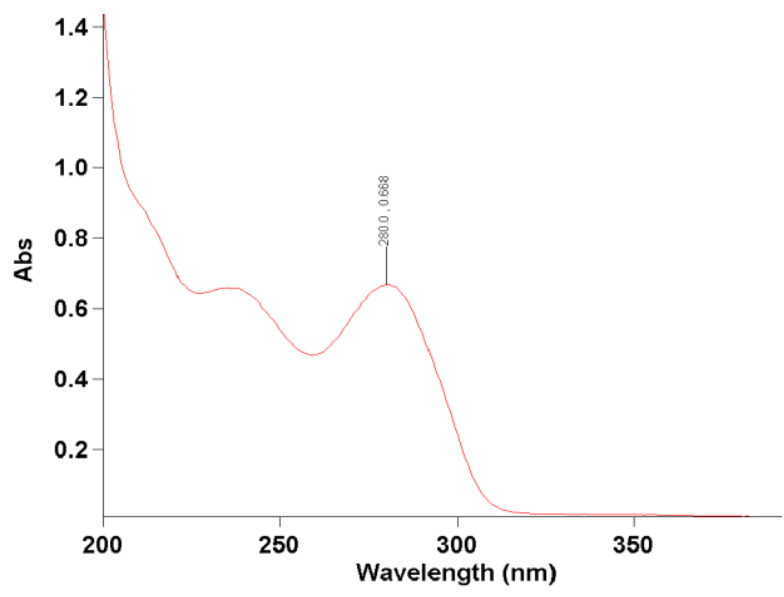

Fig. 2: Tenofovir alafenamide fumarate UV spectrum

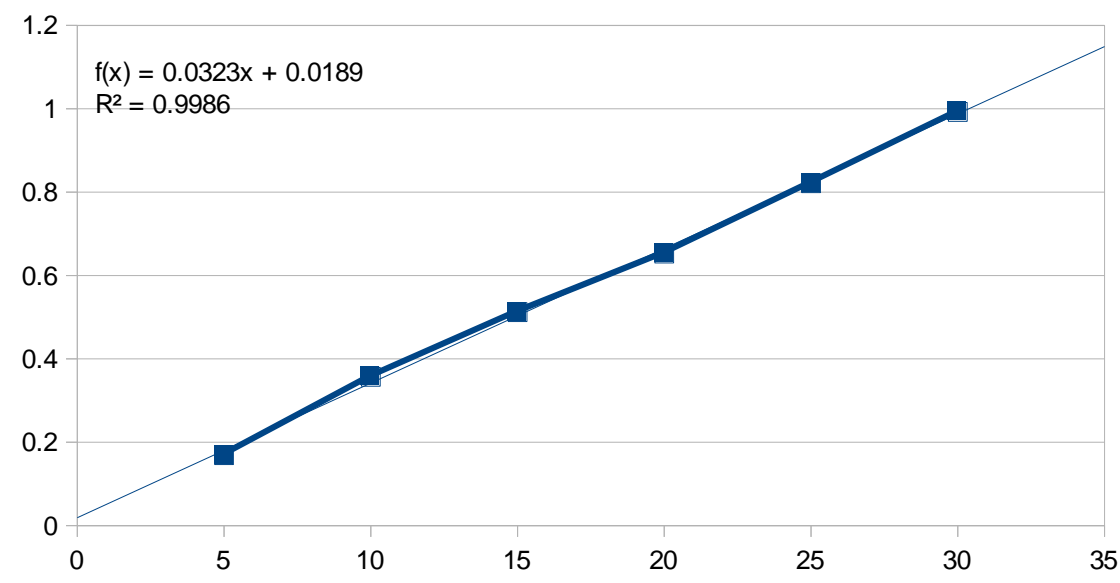

Fig. 3: Tenofovir alafenamide fumarate calibration plot

\section{Conclusion}

Suitable method developments and validation are of paramount importance to establish safety of the drug products. It is necessary for the pharmaceutical industry to know and follow the guidelines and standards regarding degradation products. By implementing the above method, pharmaceutical industries will be benefitted to meet the requirement of regulatory guidelines of stability studies like US-FDA, MHRA as well as reducing their cost and time which is required in product development. The impurities present in the drug and drug product influences the potency, safety and quality of the product. The developed UV spectroscopy method for degraded product is usually preferred over all other methods because of less equipment cost and economical advantage. It is very effortless and speedy method and can be use in QC laboratories for other procedures like Assay etc.
Journal of Pharmaceutical and Biomedical Analysis. 2002;28:1011-1040.

3. ICH, Stability Testing of New Drug Substances and Products. International Conference on Harmonisation, IFPMA, Geneva, 1993.

4. ICH, Impurities in New Drug Products. International Conference on Harmonisation, IFPMA, Geneva, 1996.

5. ICH, Specifications: Test Procedures and Acceptance Criteria for New Drug Substances and New Drug Products: Chemical Substances. International Conference on Harmonisation, IFPMA, Geneva, 1999.

6. The United States Pharmacopeia, 24th Revision, Asian Edition, United States Pharmacopeial Convention, Inc., Rockville, MD, 2000.

\section{References}

1. S. Budhavari, The Merck Index (monograph\#3565), 14, 606, (2006).

2. Monika Bakshi, Saranjit Singh. Development of validated stability-indicating assay methods-critical review. 